\title{
Learning Nursing Research Through Faculty-mentored Projects
}

Patricia K. Ravert

Brigham Young University - Provo, patricia-ravert@byu.edu

Ben Boyer

Brigham Young University - Provo

Kirsten Harmon

Brigham Young University - Provo

Holly Scoffield

Brigham Young University - Provo

Follow this and additional works at: https://scholarsarchive.byu.edu/facpub

Part of the Other Nursing Commons

\section{Original Publication Citation}

Ravert, P., Boyer, B., Harmon, K., \& Scoffield, H. (2004). Learning Nursing Research through

Faculty Mentored Projects. Nurse Educator. 29(4), 170-174.

\section{BYU ScholarsArchive Citation}

Ravert, Patricia K.; Boyer, Ben; Harmon, Kirsten; and Scoffield, Holly, "Learning Nursing Research Through Faculty-mentored Projects" (2004). Faculty Publications. 5267.

https://scholarsarchive.byu.edu/facpub/5267

This Peer-Reviewed Article is brought to you for free and open access by BYU ScholarsArchive. It has been accepted for inclusion in Faculty Publications by an authorized administrator of BYU ScholarsArchive. For more information, please contact ellen_amatangelo@byu.edu. 
$W_{\text {i }}$ deteriorating, the student nurses discussed the course of action they would take. Mrs Brown had voiced complaints that she felt light headed and ill. Working together and acting quickly, the student nurses assessed her condition, and found that the patient's vital signs were changing and that she was bleeding after the birth of her twin infants. The student nurses called upon lessons learned during their theory classes. They reviewed the medical orders, determined what nursing actions were necessary, administered the necessary and preordered medications, and continued to monitor Mrs Brown's progress. In response to the nursing actions and medications, Mrs Brown's condition improved and the situation stabilized. As the situation calmed down, a "time out" was called. The students gathered together with the faculty mentor and undergraduate nursing student research assistants (RAs) to discuss what had happened.

This scene was created after an extensive period of planning by the research team. The team, comprised of 3 RAs and 1 faculty member, had worked together for several months preparing for the scenario. The team was established to begin a facultymentored research project. Our program requires nursing students to take a course specifically on nursing re-

Authors' Affiliation: Assistant Professor (Ms Ravert), Nursing Learning Center Director (Ms Ravert); Undergraduate Research Assistants (Mr Boyer, Ms Harmon, Ms Scoffield), College of Nursing, Brigham Young University, Provo, Utah.

Corresponding Author: Ms Ravert, Brigham Young University, College of Nursing, 135 SWKT, Provo, UT 84602-5450 (Patricia_Ravert@byu.edu).

Research for this article was made possible through funding from Brigham Young University's Office of Research and Creative Activities.

\title{
Learning Nursing Research Through Faculty-mentored Projects
}

\author{
Patricia Ravert, PhD, RN \\ Ben Boyer, BS, RN \\ Kirsten Harmon, BS, RN \\ Holly Scoffield, BS, RN
}

\begin{abstract}
Baccalaureate nursing educators have incorporated nursing research content into the curriculum for many years. Our university also proposes that students bave a faculty-mentored learning experience at least once during their undergraduate education. Student research, guided by a faculty mentor, provides an excellent opportunity for students to learn about and participate in nursing research. The autbors describe a unique experience of nursing students working as research assistants in a faculty research project using a buman patient simulator.
\end{abstract}

search in which students can collaborate and participate in a faculty research project. ${ }^{1-3}$ The university encourages faculty to involve students in faculty-mentored learning experiences; however, not all students have the opportunity.

The goal for the involvement of undergraduate nursing students on the research team was for the students to develop nursing research skills by experiencing the research process through working together on a project. The students learned the fundamentals of nursing research as they functioned as RAs, actively participating throughout the research project. The students participated in 6 roles: (1) selectors and developers of scenarios, (2) recruiters of participants to the study, (3) scenario managers/implementers of intervention, (4) data collectors and managers, (5) codata analysts, and (6) disseminators of findings.

The RAs stated that the most important lesson learned was an awareness of the excitement and complexities involved in research. They learned there is much to planning and implementing a research project. The RAs learned to be attentive to details and that many decisions are made during the research process. The RAs also realized that unforeseen problems and situations may arise during research. Each situation must be carefully analyzed to determine the impact on the study and the institutional review board (IRB) agreement.

One year before the project began, the college of nursing purchased a human patient simulator (HPS). The HPS is a computer-controlled mannequin specifically designed for research and practice in the healthcare education. The HPS has breathing capabilities with lung sounds, heart sounds and pulses, dilating pupils, a swelling tongue and throat, medication recognition ability, and even a microphone and speaker in the throat of the HPS so the patient can "talk" to the nurses. The HPS creates a virtual reality in which nursing students can learn to deliver patient care in an environment that is less threatening than an actual hospital environment. The faculty mentor had obtained funding for a research project to evaluate the critical thinking skills of students after using the HPS. The budget included funds to hire student RAs. 


\section{Overview of the HPS Research Project}

The researcher was interested in using the HPS to better prepare students for clinical experiences with actual patients. Critical thinking is essential for successful nurses and is a core competency in nursing education. ${ }^{4}$ The researcher planned a project to compare before-and-after critical thinking scores of student participants who took part in educational enrichment activities using 5 patient scenarios with the HPS.

The 5 HPS scenarios involved simulated patient scenarios with medical/surgical or maternal health conditions such as chest pain or postpartum hemorrhage. When the participants arrived each week, the RAs provided a short history of the simulated patient, medical orders, and caregiver report on the patient's condition. The participants were then instructed to assess, determine, and deliver the appropriate care for the patient. As the care was given, the simulated patient responded physiologically and socially as a "real" patient may respond. The participants were then able to evaluate the situation and alter the plan of care as needed. Throughout the 45-minute scenario, the RAs guided the participants until the patient "recovered" or, in 1 case, died. After the patient care session, the participants met with the faculty mentor and the student RAs to discuss the scenario, plan of care, patient care delivered, and outcomes. The discussion was carried out in a safe and supportive environment to allow participants to learn from mistakes as well as successes.

\section{Faculty Mentoring Responsibilities}

The faculty mentor served as the project manager and principal investigator. After the faculty mentor obtained approval for the project and funding, an e-mail was sent to 96 students inviting them to apply for the student RA positions. These students had completed the fundamentals and core classes but still had 3 semesters left in the nursing program ensuring their availability through out the project. Nine students applied and were interviewed. Three students were chosen according to their availability and interest in the project. The 3 students were hired as RAs and began the next week, working 5 to 6 hours per week.

\section{Student Research Assistants' Roles}

After the RAs were hired, the faculty mentor explained in detail the project and the work began. The RAs began developing nursing research skills as they functioned in the following roles throughout the project.

\section{Selectors and Developers of Scenarios}

The determination of what patient scenarios to develop was decided after careful consideration of the point of nursing curriculum the participants would be at during the time of the study. With the assistance of the faculty mentor, the RAs chose patient and patient conditions that would be challenging but helpful in the participants' course of study. Once the 5 patient conditions were chosen, the RAs were assigned to develop specific patient scenarios using the HPS.

The HPS has many capabilities but must be programmed for each scenario so that the appropriate patient assessment findings according to the specific patient condition are displayed. The HPS was programmed to have the patient's condition gradually deteriorate or improve depending on the participants' ability to notice certain cues and indications and then carry out the necessary nursing care. The RAs not only programmed the simulator but also gathered or developed supporting documents such as scenario worksheets (Figure 1), patient history information, and audiotaped shift report and patient chart forms (including physician orders, institution protocols, and charting forms).

As when learning any new computer program, a few mistakes and "bugs" had to be worked out before the scenarios were ready for presentation. One mistake made was while beginning to run a scenario, a young healthy male patient was chosen from the HPS menu but the scenario was programmed for an older, hy- pertensive male patient. The resulting physiological parameters did not change as predicted for the medical condition and the scenario did not run as expected. The HPS had to be restarted using the correct patient to remedy the problem. To prevent the problem in the future, the appropriate patient choice was noted in the scenario documentation.

Another "bug" occurred when first learning to program the simulator. As the RAs were programming and changing different parameters in the scenario, they did not restart the HPS prior to running the revised scenario. Not restarting the HPS caused a build-up of all the previous changes and the simulator did not respond as expected. The RAs became quite frustrated and contacted the faculty mentor who was available for questions.

Upon investigation, the problem was discovered and after restarting the HPS, the scenario ran as predicted. In future programming, the RAs either restarted the HPS each time or took the parameter back to baseline prior to running the scenario. After each RA had completed the assigned scenarios, the team met and ran through each scenario. A few changes or additions were made at that time to improve each scenario.

\section{Recruiter of Participants in the Study}

After the faculty mentor had obtained IRB approval from the university, the RAs visited the second semester classes to ask for study participants. A brief overview of the project and potential benefits to the students were discussed. As there were no real incentives beyond a learning opportunity, exciting the already busy students to participate in the research study was a challenge. The RAs asked students to sign up if they were interested. A follow-up e-mail was sent to the second semester students, reminding them of the opportunity to be involved in the research project and asking them to respond via e-mail to sign up to participate. Over 2 semesters, approximately 24 of the 96 students expressed an interest in participating. 


\begin{tabular}{|c|c|c|c|}
\hline State & Events & $\begin{array}{l}\text { Expected Participant } \\
\text { Behaviors/Interventions }\end{array}$ & Questions for Participants \\
\hline Baseline/Admitting & $\begin{array}{l}\text { VS: HR } 88, \text { RR } 18 \text { unlabored, body } \\
\text { temperature } 98.6^{\circ} \text { F, BP } 104 / 68, \\
\mathrm{O}_{2} \text { sats } 96 \% \text { on RA. Patient states } \\
\text { "extremely tired." Uterus at } \\
\text { level of umbilicus. }\end{array}$ & 1. Baseline assessment & $\begin{array}{l}\text { What is the difference between a routine } \\
\text { baseline and a baseline on a postpartum } \\
\text { woman? }\end{array}$ \\
\hline $\begin{array}{l}\text { Patient is uncomfortable, } \\
\text { increased bleeding found }\end{array}$ & $\begin{array}{l}\text { Boggy uterus, } 2 \mathrm{~cm} \text { above umbilicus. } \\
\text { HR } 110, \mathrm{BP} 92 / 61, \mathrm{RR} 22, \mathrm{O}_{2} \text { sats } 92 \% \text {. } \\
\text { Loss of } 500 \mathrm{cc} \text { blood with lochia- } \\
\text { two peri pads soaked. }\end{array}$ & $\begin{array}{l}\text { 1. Massage uterus at fundus and } \\
\text { express any blood clots. } \\
\text { 2. Observe lochia for reduction in bleeding. } \\
\text { 3. Start PPH protocol. } \\
\text { 4. Notify physician and follow orders. }\end{array}$ & $\begin{array}{l}\text { Why massage the uterus? What is the } \\
\text { correct method? Why give pitocin? What } \\
\text { will you tell the physician? How often } \\
\text { should you check this patient? }\end{array}$ \\
\hline $\begin{array}{l}\text { Patient is light headed, } \\
\text { bleeding increased }\end{array}$ & $\begin{array}{l}\text { Uterus remains boggy following } \\
\text { massage, active bleeding persists. } \\
\text { HR } 130, \mathrm{BP} 84 / 56, \mathrm{RR} 28, \mathrm{O}_{2} \text { sats } 88 \% \text {. } \\
\text { Loss of } 1000 \mathrm{cc} \text { blood; } 2 \text { more pads } \\
\text { soaked, blood pooling under patient } \\
\text { on chux. }\end{array}$ & $\begin{array}{l}\text { 1. Increase pitocin drip. } \\
\text { 2. Continue to massage uterus. } \\
\text { 3. Give } \mathrm{O}_{2} \text {. } \\
\text { 4. Assess continued bleeding. } \\
\text { 5. Get blood units ready. } \\
\text { 6. If bleeding persists, get physician's } \\
\text { orders for continued treatment. }\end{array}$ & $\begin{array}{l}\text { Why are the patient's } \mathrm{O}_{2} \text { sats falling? How } \\
\text { would you know what type of blood to } \\
\text { request? What is bimanual compression of } \\
\text { the uterus and who would do this } \\
\text { procedure? }\end{array}$ \\
\hline $\begin{array}{l}\text { Patient is still somewhat light- } \\
\text { headed, but is feeling better }\end{array}$ & $\begin{array}{l}\text { Uterus firm. Bleeding slows. HR } 88 \text {, } \\
\text { BP } 104 / 70 \text {, RR } 18, \mathrm{O}_{2} \text { sats } 96 \% \text {. }\end{array}$ & $\begin{array}{l}\text { 1. Change chux/sheets. } \\
\text { 2. Provide comfort, reassurance. }\end{array}$ & How would you feel following this incident? \\
\hline $\begin{array}{l}\text { Background/Patient History: Mrs } \mathrm{H} \\
\text { Hemmy suffered from pregnancy-in } \\
\text { Blood pressure was carefully moni } \\
2 \text { years. No major medical complic }\end{array}$ & $\begin{array}{l}\text { age is a } 23 \text {-year-old white female } 16 \text { hours postp } \\
\text { pertension with } \mathrm{BP} \text { readings reaching } 155 / 90 \text { bef } \\
\text { g labor. A pit drip was used to augment labor. Pe } \\
\text { tient's mother delivered } 6 \text { children with minimal cc }\end{array}$ & $\begin{array}{l}\text { tum following normal vaginal delivery of twins at } 37 \mathrm{w} \\
\text { e delivery. Labor began spontaneously and she was } \\
\text { ent is now in mother/baby unit with husband, babies } \mathrm{i} \\
\text { plications. }\end{array}$ & $\begin{array}{l}\text { ks gestation. The twin boys are her first children. } \\
\text { e to deliver vaginally, but only after } 16 \text { hours of labor. } \\
\text { hursery. Patient History: Healthy young female, married }\end{array}$ \\
\hline
\end{tabular}

Figure 1. Example of scenario worksheet (postpartum hemorrhage). 


\section{Scenario Managers/}

\section{Implementers of Intervention}

Through managing the scenarios, the RAs learned to implement the educational enrichment activities on the HPS. Each of the 5 weeks, the RAs set the scene for the scenario, striving to simulate the real environment as much as possible. Setting the scene included dressing the simulator (clothing, wigs, and makeup), applying the appropriate dressings, inserting tubes (IVs and catheters), and obtaining the appropriate forms for documentation.

With the guidance of the faculty mentor, the RAs conducted the scenarios each week throughout the study. During the scenarios, the RAs served in different roles. One RA would be at the computer controlling the HPS, while another RA, and sometimes the faculty mentor, would monitor the participants and guide the students as they cared for their "patient." A third RA or the faculty mentor would give voice to the patient or act as the attending physician. Throughout each scenario the RAs helped to coach the participants by fielding questions and providing guidance and direction in decisions regarding nursing care for the patient.

\section{Data Collectors and Managers}

In conjunction with the faculty mentor, RAs scheduled times for the scenarios and the initial data collection for each of the 24 participants prior to the first scenario. At the initial meeting, the RAs obtained written consents from the participants and administered the critical thinking instruments and demographic survey. With the help of the faculty mentor, the RAs calculated the critical thinking scores and coded the demographic information. The RAs entered the demographic information and the scores from the critical thinking instruments into a statistical analysis computer program.

\section{Codata Analysts}

At the conclusion of the 5 scenarios, the RAs administered to the participants the postcritical thinking instruments and a survey to evaluate the use of the HPS in the augmentation of nursing education. Again the RAs assisted in the calculation of scores, coding, and data entry. The RAs assisted in data analysis by compiling the data from the survey and reviewing the comments for common themes from the participants. The faculty mentors taught the RAs how to run the quantitative statistics using computer software. The interpretation of the findings was discussed and results documented during a team meeting.

\section{Disseminators of Findings}

Not only were the student RAs involved in every aspect of the research project, but they were also involved in the presentation and publication of the results as well. In addition, the RAs presented at a national convention for simulator users as well as at a national conference for undergraduate research. 5,6 A manuscript reporting the results of the research project is under review by a peer-reviewed journal.

\section{Skills Learned and Benefits for the Research Assistants}

The RAs learned that research can be exciting as well as complex. This was a fairly simple project but the RAs learned that the rigors of research procedures and standards are important to follow. One RA stated, "I would sum up research as planning, planning, and more planning...and then doing." Each RA stated they gained a greater knowledge base and understanding of nursing in general. Developing and conducting the scenarios deepened their understanding of pathophysiology and how disease presents itself in the patient. The RAs had to study and be prepared to coach the participants if needed during the scenarios. Conducting the scenario sessions and participants' discussion increased the RAs understanding of the nursing process.

The RAs developed research skills during the project. Project planning and management skills increased as the RAs kept track of scheduling, data, and set-up, and conducted the weekly scenarios. Each RA gained new computer skills including programming the HPS scenarios, building the database in a statistical analysis computer pro- gram, and entering data. The RAs ran basic descriptive statistics on the data set and interpreted the results. The faculty mentor helped to run other statistical tests and assisted the students to apply the statistical analysis methods they learned in their nursing research course. The RAs learned to disseminate the findings in a variety of ways such as presenting a podium presentation using a PowerPoint, publishing an abstract, and preparing a manuscript for publication.

The RAs felt it was a great benefit to be directly involved with a faculty member. The faculty member had the resources available to make the research project a reality. The RAs not only worked on the project with the mentor but also gained support from the faculty member throughout the rest of their nursing curriculum.

Because the faculty mentor had obtained a grant for the study, the RAs were monetarily compensated for their time. The RAs were not used as "free labor" as is sometimes done with students involved in faculty research. ${ }^{1}$

The RAs state that participating in a faculty research project was an invaluable part of their nursing education. They were able to experience the research process from beginning to end, which has instilled in them an excitement for further nursing research possibilities. Through their involvement with the faculty mentor they were involved in the steps one must take in order to approve a research idea to develop, conduct, and finalize a research project.

\section{Suggestions for Faculty}

Undergraduate nursing students are able to successfully fulfill the role of RAs and learn research skills if they are given the guidance and opportunity to do so. Most research projects could benefit from the inclusion of student RAs. The faculty mentor found the following points helpful while working with RAs during this project:

- Select/hire students who have sufficient time left in the nursing program so that they will be available throughout the project.

- Use communication systems such as e-mail to keep in contact with RAs. 
- Provide initial overview and updates of the project with research team.

- Teach specialized skills needed for project (such as programming the HPS in this project).

- Develop timeline and deadlines for research project components.

- Hold weekly research team meetings to review assignments, progression on timeline, and plan for next project component.

- Meet 1-on-1 regularly with each RA to facilitate the assignments.

- Provide resources for the project.

- Review work by RAs to ensure accuracy and appropriateness.

- Look for opportunities such as local or regional venues for RAs to display or present their work.

- Function as the coordinator for manuscript or presentation development.

These suggestions support the RAs and kept the project progressing. As the students became more proficient, less faculty time was necessary to oversee the RA work.

\section{Conclusion}

Many undergraduate students are intimidated by research. ${ }^{1}$ However, participating in a faculty research project may ease their fears as well as increase their confidence in their ability to be involved in and conduct nursing research in the future. Using undergraduate nursing students as RAs, the faculty member was able to complete the project and mentor the RAs also. The RAs strongly recommend that undergraduate students become involved in faculty research projects as the opportunity arises. They suggest to university faculty across the nation to provide more of research opportunities for their students. By doing so, more students will be able to have the positive experience they had as they begin to appreciate the value and importance of research to the nursing profession.

\section{References}

1. Mandleco BL, Schwartz R. Faculty/student collaboration: An approach to teaching nursing research. Nurse Educ. 2002;27(2):61-64.

2. Conn VS. Strategies for teaching nursing research: Involving students in advance practice nurses' and nurse educators' collaborative research. Western J Nurs Res. 1995;17(5):574-577.

3. Porter EJ, Mansour TB. Teaching nursing research to undergraduates: A text analysis of instructors' intentions. Res Nurs Health. 2003;26:128-142.

4. American Association of Colleges of Nursing (AACN). The Essentials of Baccalaureate Education for Professional Nursing Practice. Washington, DC; AACN; 1998.

5. Boyer B, Scoffield H, Harmon K. Research experiences with the human patient simulator and undergraduate nursing students [abstract and podium presentation]. National Conference on Undergraduate Research, University of Utah, Salt Lake City, Utah, 347; 2003.

6. Boyer B, Scoffield H, Harmon K. Nursing research with the HPS: Fun, splats, facts, and future plans. HPSN 2003, Tampa, Fla; 2003. 